\title{
Selembar Motif Berbicara: Lomba Desain Batik Motif Kopi 2017
}

\author{
L. Dyah Purwita Wardani SWW \& Hat Pujiati \\ Fakultas Ilmu Budaya- Universitas Jember \\ dyahpw.sastra@unej.ac.id
}

\begin{abstract}
Abstrak
Kopi menjadi salah satu tema yang masuk ke dalam Rencana Induk Penelitian Universitas tahun 2016-2020. Dalam rangka meningkatkan riset tentang kopi, maka diadakannya JICC (Jember International Coffee Conference) pada tanggal 9-11 November 2017. Kegiatan ini merupakan kerjasama antara Pemerintah daerah Bondowoso dan Universitas Jember. Selain mendeklarasikan diri sebagai republik kopi, Bondowoso juga sedang menggalakkan industri kreatif dalam bidang batik. Kegiatan IPTEK yang kami kerjakan dalam upaya ikut mensukseskan JICC serta untuk meningkatkan daya saing batik Bondowoso. Lomba ini bertujuan untuk menjaring desainer motif batik nasional yang bisa diimplementasikan pada produk pengrajin batik khas Bondowoso dengan mengangkat keseimbangan antara kekayaan flora, fauna, dan aktivitas sosial yang berkaitan dengan kopi. Selain itu, menonjolkan desain kopi pada batik khas Bondowoso salah satu cara promosi daerah yang akan berdampak pada peningkatan kesejahteraan masyarakat khususnya para pengrajin batik. Selain membantu eksistensi Bondowoso di kancah nasional, kegiatan ini juga merupakan upaya Universitas Jember untuk mengangkat kopi yang notabene sumber hidup masyarakat di sekitar universitas ke ranah masyarakat internasional.
\end{abstract}

Kata kunci: Batik, Lomba desain, Kopi, Bondowoso

\section{PENDAHULUAN}

\section{a. Batik Bondowoso dan Kopi}

Bondowoso sebagai daerah kabupaten dengan tingkat kemiskinan tertinggi di Jawa Timur pada tahun 2015 menjadikan kabupaten ini menjadi prioritas negara untuk ditumbuh kembangkan. Akan tetapi, Bupati Bondowoso, Drs. H. Amin Said Husni menegaskan bahwa Bondowoso bukanlah daerah miskin (https://www.bangsaonline.com/berita/171l4/bondowoso-berada-di-urutan- 
pertama-dalam-daerah-tertinggal-di-jatim). Predikat daerah tertinggal itu disebabkan salah satunya karena Bondowoso bukan jalur transit seperti daerahdaerah lain. Bondowoso tidak memiliki laut, dia berbatasan dengan Banyuwangi di utara, Banyimut, Probolinggo di bagian barat dan Jember di sisi Selatan. Posisi tersebut menyebabkan Bondowoso kurang kontak dengan daerah luar, bahkan jalur transportasi seperi bus antar kota juga sangat terbatas (http://indikatoronline.com/2016/04/14/daerah-tertinggal-bukan-berartibondowoso-miskin/ - 30 Juli 2017; 15 WIB). Terkait dengan predikat sebagai daerah tertinggal tersebut, Bupati Amin bertekat untuk membawa Bondowoso keluar dari status daerah tertinggal. Upaya kerjasama dengan berbagai pihak juga dilakukan termasuk dengan Universitas Jember sebagai pusat pengetahuan akademis di daerah Tapal Kuda selatan (Jember-Bondowoso- Situbondo dan Banyuwangi).

\section{b. Identitas Kedaerahan yang Belum Kuat}

Posisi Bondowoso yang ada di antara Jember, Situbondo dan Banyuwangi menyebabkan kontak dengan masyarakat luar berintensi rendah. Akses pasar menjadi terbatas, oleh sebab itu masyarakat Bondowoso membutuhkan ke-khasan yang kuat pada produk kerajinannya. Bila Jember telah cukup terkenal dengan tembakau yang dihasilkannya dan menjadi ikon pada produk-produknya, potensi Bondowoso dengan popularitas kopinya bisa dijadikan kekuatan dalam membangun identitas Bondowoso yang mulai berkembang. Secara nasional kopi Ijen Bondowoso telah diakui kenikmatannya dan berdampak pada nilai ekonomisnya. Novel Filosofi Kopi oleh Dewi Lestari mengangkat kopi dan laris di pasar pembaca Indonesia bahkan novel tersebut ditransformasi ke dalam Film berjudul sama, bahkan film Filosofi Kopi 2 saat ini tengah tayang di bioskop nasional. Produksi film yang berlanjut tersebut menunjukkan keberhasilan pada film pertama, film yang mengangkat Kopi Tiwus di Ijen. Dengan demikian kopi Bondowoso sebenarnya telah cukup diakui di kancah nasional. Bila Bondowoso dapat membangun identitas kedaerahan yang cukup kuat maka potensi mendatangkan orang luar ke Bondowoso meningkat, sektor pariwisata bisa berkembang dan pada akhirnya mampu mendatangkan investor untuk membantu pembangunan Bondowoso.

\section{c. Industri Kreatif Batik}

Usaha Bondowoso dalam membangun identitas sebenarnya telah bergerak di bidang kerajinan batik. Hanya saja batik Bondowoso belum memiliki desain yang menarik pangsa pasar. Para pengrajin batik tulis Bondowoso sebenarnya telah berusaha mengimplementasikan identitas kopi mereka dalam produknya. Sayangnya desain kopi yang cantik di atas kertas desain tidak berakhir cantik pula ketika desain itu ada di atas kain. Biji-biji kopi pada Batik Bondowoso kurang 
menyokong kekhasan daerah, bahkan wujud daun kopi pada desain tersebut lebih menyerupai tembakau.
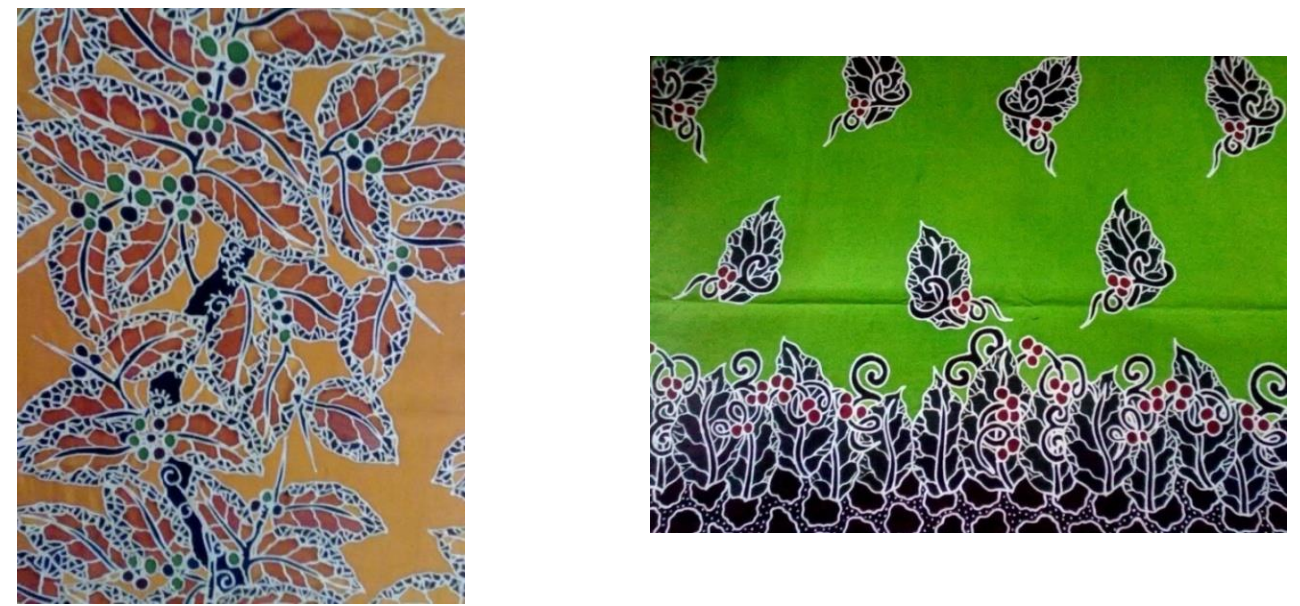

Gambar 1 \& 2 : motif kopi yang ada pada batik khas tamanan Bondowoso (http://batiktamanan.blogspot.co.id/2014/12/KOLEKSI-BATIK-TULIS-KHASTAMANAN-BONDOWOSO-3.html ( 29 Juli 2017) )

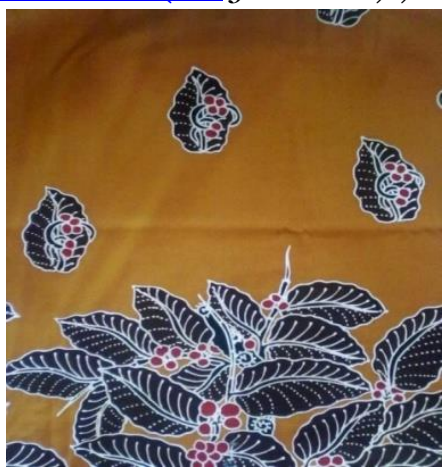

Gambar 3: motif kopi yang ada pada batik khas tamanan Bondowoso (http://batiktamanan.blogspot.co.id/2014/12/KOLEKSI-BATIK-TULIS-KHASTAMANAN-BONDOWOSO-5.html)

Motif-motif batik tersebut pada gambar 1, 2 dan 3 di atas adalah produk batik tulis yang ada di Tamanan Bondowoso, motif-motif tersebut sebenarnya ingin menggambarkan kopi. Hanya saja motif kopi gambar $1 \& 2$ memiliki daun yang begitu ramai asesoris sehingga tidak mudah dikenali bahwa itu kopi. Bahkan gambar 2 memiliki daun yang mirip daun tembakau. Gambar 3, motif daun pada pinggiran kain sudah mirip daun kopi, namun daun pada bagian tengah yang mirip pada gambar 2 justru mengaburkan keutuhan referensi pada gambar-gambar tersebut. Gambar buah yang hanya berupa bulatan-bulatan merah juga bisa menggiring pada referensi selain kopi bila pengamatnya bukan orang di daerah yang akrab dengan kopi. 
Kegagalan desain ini mendorong tim kami untuk membantu menyelesaikan masalah desain tersebut. Dengan sebuah event kompetisi yang berskala nasional. Langkah ini dianggap perlu untuk membantu mewujudkan keinginan pemda Bondowoso memiliki desain batik yang khas. Sesuai dengan tema lomba yaitu Coffee for Welfare maka potensi daerah pada bidang perkebunan kopi dipandang sebagai tema yang tepat untuk digandeng dalam kerjasama ini. Skala nasional kami pilih dengan pertimbangan bahwa perkara desain batik bukan perkara sederhana. Ide-ide pendesain batik nasional yang tersebar di Indonesia hendak kami tampung untuk dipilih yang paling mewakili kopi Bondowoso dan mudah diterapkan pada kain yang hendak dibatik.

Terkait dengan permasalahan yang telah diuraikan di dalam bab sebelumnya, maka solusi yang kami tawarkan dalam kegiatan ini adalah dengan memilih sepuluh desain batik aplikatif pada kain mori. Lomba ini urgen untuk dilakukan mengingat kebutuhan konstruksi identitas Bondowoso dalam menyokong promosi daerah dan menarik pendatang untuk berkunjung ke Bondowoso. Capaian yang lebih jauh bila target yang kami rencanakan tercapai adalah datangnya investor ke Bondowoso dengan mengedepankan kekuatan potensi daerah

Inovasi yang kami tawarkan dalam pemecahan masalah yang dihadapi Pemda Bondowoso dan pengrajin Batik di daerah tersebut adalah dengan pencarian desain yang menawarkan identitas Bondowoso dan mudah diaplikasikan ke kain mori sebagai bahan dasar batik. Kriteria penilaian lomba desain tersebut adalah dengan mempertimbangkan orisinalitas karya. Adapun orisinalitas/ keaslian karya harus mencakup a) keunikan motif dan penentuan ciri khas motif, b) kreativitas (gagasan atau ide) tidak meninggalkan stilasi flora dan fauna seputar tanaman kopi, biji kopi, penyajian Kopi, atau aktivitas manusia terkait kopi (aspek sosial) yang diwujudkan dalam filosofi c) harmonis dan estetis saat di aplikasikan dalam kain.

\section{d. Meningkatkan Kualitas Batik Kopi Bondowoso secara Estetis}

Desain batik merupakan ekspresi seni yang cukup tinggi. Batik tulis dikerjakan oleh pembatik sebagai industri rumah tangga. Ketika batik dikerjakan masyarakat, desain yang walau dirancang oleh orang luar, namun kelembutan goresan, menunjukkan karakter kreator yang merupakan anggota sebuah masyarakat. Seorang desainer batik tentu tidak mendesain batik sejadinya namun setidaknya melakukan observasi tentang masyarakat yang akan menggunakan desain tersebut serta karakteristik masyarakatnya. Ketika desain tersebut ada di tangan pembatik, antara desain dan goresan akan terpadu dalam estetika. Dengan demikian kualitas estetik batik kopi Bondowoso akan meningkat. 
Metode yang akan kami pakai dalam mencapai target untuk menjawab permasalahan sebagaimana dijelaskan pada bab-bab sebelumnya adalah sebagai berikut:

1. Pengadaan Lomba dengan tema Coffee for Welfare, pendaftaran lomba ini gratis mengingat target kami sebagai tim penyelenggara bersama tim JICC bertujuan untuk menjaring desain batik kopi sebanyak mungkin di tingkat nasionall 2.Syarat lomba yang terpampang dalam leaflet:

a. orisinalitas/ keaslian karya

b. keunikan motif dan penentuan ciri khas motif

c. filosofi : kreativitas (gagasan atau ide) tidak meninggalkan stilasi flora dan fauna seputar tanaman kopi, biji kopi, penyajian Kopi atau aktivitas masyarakat terkait kopi di Bondowoso (aspek sosial)

d. Harmonis dan estetis saat di aplikasikan dalam kain.

\section{PEMBAHASAN}

Jangka waktu yang diberikan kurang dari satu bulan, selama bulan Oktober 2017 hingga 2 November 2017, namun animo peserta lomba desain batik motif kopi cukup banyak. Walau pun pada minggu pertama, panitia sempat khawatir karena baru terdaftar 6(enam) peserta. Maka penyebaran informasi semakin kami gencarkan, tidak hanya menggunakan leaflet kesekolah-sekolah SMA dan SMK di Jember, namun juga menggunakan kekuatan sosial media facebook, dan juga WA. Akhirnya mendapatkan partisipasi dari 166 desain yang berasal dari berbagai daerah: Banjarnegara,Bondowoso, Boyolali, Bandung, Blitar, Ngawi, Nganjuk, Jepara, Jember, Pekalongan, Purbalingga Situbondo, Surabaya, Solo, Sukoharjo, Yogyakarta, Kudus, , Lumajang. Desain yang masuk ada 166 desain namun yang lolos desk evaluasi 163 desain. 2 (dua) desain melampui batas akhir pengiriman dan 1(satu) merupakan desain baju sehingga ketiga desain ini tidak bisa diikutkan dalam penjurian.

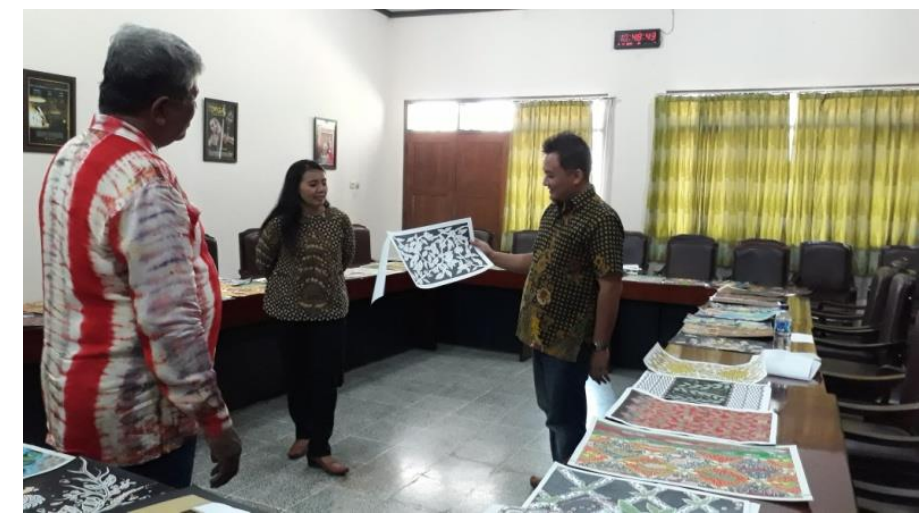


Kegiatan Penjurian di Fakultas Ilmu Budaya- Universitas Jember

Pada Pada hari Jumat, tanggal 3 November 2017 telah dilakukan penjurian bertempat di Fakultas Ilmu Budaya (FIB) Universitas Jember. Ketiga juri ini,Drs. Harry Kresno S, MM; Soekma Yeni A S.Sn, M.Sn; dan Adi Kurniawan, merupakan akademisi dan praktisi di bidang batik.

Setelah para juri meneliti dan mempertimbangkan hasil karya desain maka dewan juri memutuskan dan menetapkan pemenang sebagai berikut:

\begin{tabular}{|c|c|c|c|c|}
\hline $\mathrm{NO}$ & PEMENANG & NILAI & JUDUL KARYA & NAMA PESERTA \\
\hline 1. & Juara I & 1005 & Penikmat Kopi Sejati & $\begin{array}{ll}\text { Galing } & \text { Bondan } \\
\text { Gunawan } & \end{array}$ \\
\hline 2. & Juara II & 992 & Kopi Arabika & $\begin{array}{l}\text { Nisfi } \quad \text { Ghoirotun } \\
\text { Nasuha }\end{array}$ \\
\hline 3. & Juara III & 991 & $\begin{array}{l}\text { Kurangkai Impian } \\
\text { Lewat Secangkir Kopi } \\
\text { Pilihan }\end{array}$ & $\begin{array}{ll}\text { Noer } & \text { Aminatus } \\
\text { Sya'diyah } & \end{array}$ \\
\hline 4. & Juara IV & 975 & Kopi Klasik & Suliswati \\
\hline 5. & Juara V & 965 & Bighi Dumpa & AC Wiranti \\
\hline 6. & $\begin{array}{l}\text { Hadiah } \\
\text { hiburan }\end{array}$ & & $\begin{array}{l}\text { 1.Biji Kopi Mentah } \\
\text { 2. Kopi Luwak } \\
\text { 3. Level Roasting } \\
\text { 4. Sajian Batik Kopi } \\
\text { 5. Ayo } \\
\text { Membudidayakan Kopi }\end{array}$ & $\begin{array}{l}\text { 1. Antonia Regita } \\
\text { Wijaya } \\
\text { 2. Zalzuli Fachrur } \\
\text { Rohmanu } \\
\text { 3. Donny A Waluyo } \\
\text { 4. Friska Yuli Anita } \\
\text { 5. Amanda Azzahra }\end{array}$ \\
\hline
\end{tabular}

Menurut dewan juri kesepuluh desain diatas mendapatkan nominasi karena:

a. Efisiensi produksi untuk tehnik cap/colet

b. Filosofi menggambarkan tema

c. Memungkinkan untuk menjadi pola ready to wear untuk keperluan fashion

d.Memungkinkan diproduksi secara massal melihat paduan warna yang dipakai dan bisa dilakukan dengan kemampuan para pembatik sasaran.

e. Komposisi visual memenuhi unsur-unsur unity, balance, ritme dan harmonis

Kekuatan kesepuluh nominator terutama terletak pada filosofi yang disampaikan. Pada juara satu dengan karya yang berjudul Penikmat Kopi Sejati, Galing menyampaikan bahwa motif batiknya menggambarkan kehidupan hewan luwak yang menjadi sahabat bagi para petani. Kopi Luwak membantu para petani dalam memanen kopi,sekaligus mengupas kulit kopi. Hewan ini akan memakan daging buah kopi yang sudah matang,dan mengeluarkan biji kopi lewat kotor- 
annya. Biji inilah yang di ambil para petani kopi Bondowoso untuk di bersihkan dan di masak, untuk kemudian digiling sampai halus. Kopi Luwak, memiliki cita rasa yang unik dan nikmat. Aromanya yang harum mengundang selera bagi penikmat kopi sejati.Kopi Luwak menjadi komoditi lokal maupun export yang sangat dicari dan digemari masyarakat baik mancanegara maupun lokal di segala usia.

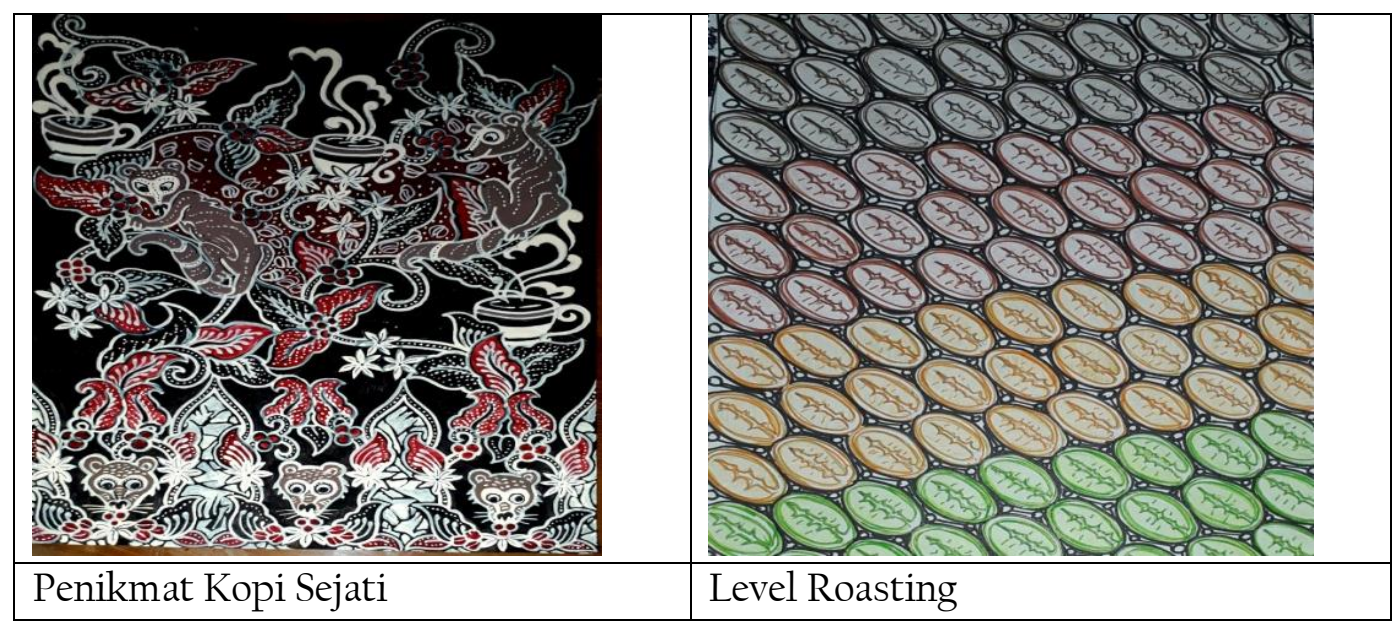

Pada Batik Penikmat Kopi Sejati,Warna coklat kehitaman menggambarkan kemapanan sosial masyarakat Bondowoso sebagai petani kopi,dan juga menggambarkan kesuburan dan kemakmuran. Warna Merah, Menggambarkan semangat,keberanian,dan kesungguhan para petani kopi di Bondowoso dalam mengolah hasil bumi ,terutama kopi.Warna Putih kekuningan ( Putih Gading ) menggambarkan kemakmuran dan sukacita.Gelas atau cangkir kopi, menggambarkan kebersamaan,kekeluargaan,dan keharmonisan bermasyarakat. Dengan secangkir kopi yang nikmat,hubungan sosial terjalin erat. Kopi menjadi suguhan minuman yang memasyarakat.

Donny, pemilik Bedhag Kopi, menawarkan karyanya yang berjudul Level Roasting. Karyanya merupakan proses dalam pengolahan kopi. Biji mentah (green bean) akan diubah menjadi roasted bean yang memiliki karakteristik beraroma unik dan kaya rasa. Sama seperti perjalanan hidup manusia.

1. Green bean : seperti anak yang baru lahir

2. Light Roast : seperti remaja yang baru bersinar namun masih labil

3. Medium roast: profile yang lebih seimbang dari segi rasa seperti orang dewasa yang sudah tahu jati diri.

4. Dark roast : kopi yang sudah mengalami proses panjang, mulai dari berat yang berkurang, warna lebih gelap, rasa cenderung pahit. Pada tahap ini membuat orang 
berpikit "sayang sekali jika kopi seperti ini di roasting gelap “. Demikianlah memahami karakter kopi sama halnya manusia harus bisa memahami karakter dirinya, agar tidak menyesal di kemudian hari.

\section{KESIMPULAN}

Kekuatan sebuah batik tidak hanya pada pola maupun corak warna yang dibubuhkan namun pada sebuah cerita yang ditawarkan. Ketika batik mampu bercerita maka orang akan lebih tertarik untuk membelinya. Seperti dikatakan oleh Adi Kurniawan, pemilik galeri Sisik Melik, batik yang dibuatnya biasanya menggali nilai-nilai lokal di masyarakat setempat. Maka ia menawarkan batik sulur yang terinspirasi ketika dia ke kawah Ijen. Demikian juga dengan pengalaman ibu Noer, juara ketiga, konsumen beliau menyukai desain batiknya karena unik dan personal. Maka istilahnya adalah batik custom.

Jadi batik bukan hanya selembar kain bermotif. Demikian juga dengan batik motif kopi yang kami tawarkan adalah batik yang bercerita. Ada sebuah harapan juga nilai- nilai yang termaktub di dalam desain batik ini. Dengan inspirasi cerita didalamnya, diharapkan akan mampu memberikan tawaran nilai- nilai baru yang bisa dimiliki oleh batik Bondowoso.

\section{DAFTAR PUSTAKA}

https://www.bangsaonline.com/berita/17ll4/bondowoso-berada-di-urutanpertama-dalam-daerah-tertinggal-di-jatim diunduh 30 Juli 2017; 15 WIB http://indikatoronline.com/2016/04/14/daerah-tertinggal-bukan-berarti-

bondowoso-miskin/ diunduh 30 Juli 2017; 15:00 WIB (http://batiktamanan.blogspot.co.id/2014/12/KOLEKSI-BATIK-TULIS-KHASTAMANAN-BONDOWOSO-3.html diunduh 29 Juli 2017;20.00WIB

(http://batiktamanan.blogspot.co.id/2014/12/KOLEKSI-BATIK-TULIS-KHASTAMANAN-BONDOWOSO-5.html diunduh 29 Juli 2017;20.00WIB 